ORIGINAL ARTICLE

\title{
Seroepidemiology Study of Cytomegalovirus and Rubella among Pregnant Women at St. Paul's Hospital Millennium Medical College, Addis Ababa, Ethiopia
}

\author{
Mamuye Yeshwondm', Nigatu Balkachew², Bekele Delayehu², Getahun \\ Mekonen $^{3}$
}

\begin{abstract}
BACKGROUND: Maternal cytomegalovirus (CMV) and rubella infections have adverse neonatal outcomes. Both CMV and rubella are more widespread in developing countries and in communities with lower socioeconomic status. The aim of this study was to investigate sero-prevalence of CMV and rubella infection and associated possible risk factors.

METHOD: Using cross sectional study design a total of 200 pregnant women were consecutively recruited starting from June and July 2014. Blood samples were collected, and structured questions were used to gather socio-demographic and risk factor related data. ELISA was used to detect CMV (IgG, IgM) and rubella IgM. SPSS version 20 was used to analyze the data, and regression was also performed. RESULTS: Out of 200 pregnant women, 88.5\%, 30(15.5\%) and 4(2.0\%) were CMV-IgG, CMV-IgM, and rubella-IgM positive, respectively. Women who were immune/positive only for IgG were $73.5 \%$. The second group was those with primary infection [IgG (+) plus IgM (+)] and this consisted of 15.0\% participants. Eleven percent of the participants were at high risk for primary infection during their pregnancy. One pregnant woman was identified as having a recent primary infection. In this study, no statistically significant association was detected between CMV infection with idependent factors (pvalue $>0.05$ ).

CONCLUSION: In addition to detection of high prevalence of CMV, detecting recent infection of rubella worsens the outcome of the disease. Rubella vaccine should be taken into consideration after large scale surveillance. However, screening of all pregnant women for CMV infection may not be cost-effective as in the countries with high seropositivity.
\end{abstract}

KEYWORDS: Cytomegalovirus, Human cytomegalovirus, Rubella, Seroprevalence, Pregnancy

DOI: http://dx.doi.org/10.4314/ejhs.v26i5.4

\section{INTRODUCTION}

Human cytomegalovirus (CMV) is a member of the family Herpesviridae and belongs to the subfamily betaherpesviridae. CMV has worldwide distribution, infects humans of all ages and all socioeconomic groups, and with no seasonal or epidemic patterns of transmission (1). It is the most common cause of congenital infection with birth prevalence of about $0.5 \%$ (range 0.2-2.5 percent), and a common cause of deafness and intellectual impairment worldwide $(2,3,4)$.
In utero transmission of CMV can occur following primary maternal infection during pregnancy but can also occur in women with natural immunity, either because of the reactivation of latent virus or by re-infected with a different strain (5). Postnatally, CMV is also transmitted from mother to child through breastfeeding and close contact (6). The transmission risk is the proportion of mothers undergoing a primary infection in a given trimester and/or the preconception period who

\footnotetext{
${ }^{1}$ St.Paul's Hospital Millennium Medical College. Microbiology, Immunology\&Parasitology, Addis Ababa, Ethiopia

${ }^{2}$ St.Paul's Hospital Millennium Medical College. Gynecology, Addis Ababa, Ethiopia

${ }^{3}$ Ethiopian Public Health Institute Polio and Measles Laboratory, Addis Ababa, Ethiopia

Corresponding Author: Mamuye Yeshwondm, Email: y_mamuye @yahoo.co
} 
transmitted CMV to the fetus (7). While CMV has asymptomatic infection, rubella infection is mild or self limiting disease, transmitted through respiratory system and to growing fetus through placenta (8).

Maternal infection especially during the first trimester is associated with adverse neonatal outcome which encompass heart disease, cataract and deafness collectively known as congenital rubella syndrome which had a major neonatal morbidity and burden to families (9). Although incidence of rubella infection is reduced worldwide, some African countries like Mozambique still have a high incidence (95.3\%) $(10,11)$. Rubella vaccine is cost-effective and costbeneficial. Therefore, since the year 2000 WHO proposed an introduction of rubella vaccine program in each country (12). Studies conducted in other parts of the world have mentioned about risk factors, primarily in women of childbearing age. However, no data exists regarding risk factors associated with CMV acquisition in the setting among pregnant women. Pregnant women engage in personal behaviors (such as saliva sharing behaviors, including sharing drinks, kissing and sexual activity) and have exposures (such as care of infants and toddlers, gestations, abortions, parity, and group living situations), all of which may place pregnant women at risk. Given the likelihood of an effective vaccine in the near future (13), it is critical to understand the prevalence and risk factors for CMV infection among pregnant women.

The basic data concerning CMV and rubella infections during pregnancy is important for health planners and care providers. Therefore, the objective of this study was to determine the seroprevalence, associated risk factors of CMV and rubella infection among pregnant women.

\section{MATERIALS AND METHODS}

A cross sectional study was conducted in St. Paul's Hospital Millennium Medical College (SPHMMC), Addis Ababa, Ethiopia. It is an urban setting and tertiary hospital for Ethiopian and teaching hospital for national and international students. The hospital provides out- and in-patient services with 370 beds. Accordingly, patients being seen at SPHMMC come from all over the Northern, Western, Southern and Eastern parts of
Ethiopia. The sample size for the study was calculated using the formula $(n=(z \alpha / 2) 2 p(1-p) /$ d2) for estimating a single population proportion at $95 \%$ confidence interval $(\mathrm{CI})(\mathrm{Z} \alpha / 2=1.96), 5 \%$ margin of error, and $10 \%$ non-respondents rate based on IgM seroprevalence of CMV from a study in Sudanees pregnant women $6.0 \%$ (14). Therefore, the minimum sample size for seroprevalence of CMV survey was 97 . However, a total of 200 study participants were consecutively selected to maximize the findings and to get a conclusive information about seroepidemiology of cytomegalovirus among pregnant women in the study settings.

All pregnant women between 17-37 years of age, and who were volunteer to give consent to participate in the study were eligible to be included. Pregnant women aged less than seventeen were excluded from the study.

Data collection: Venous blood samples were collected from 200 pregnant women attending antenatal clinic between June 1 and July 30, 2014. Samples were collected under aseptic conditions and transported using ice-box to Ethiopian Public Health Institute (EPHI), and the experiment was performed in EPHI.

A total of 26 items of standard structured questions were designed to collect information regarding socio-demographics and risk related data; such as history of abortion, frequency of abortion, number of children in the household, number of disabled children, long time fever, presence of mentally retarded child in the household, gestational age and parity. The questionnaire was first developed in English and translated into Amharic (the local language), and then pre-tested (to improve the quality and clarity of errors during translation) in non-selected health institutions among fifty mothers to assess the content validity, appropriateness and question comprehensibility. The questionnaire was revised accordingly. Three data collectors from the institution in the study area were selected. Training was given for the data collectors for two day on how to conduct the interview, content of the questionnaire, data quality, and ways to approach respondents. The first author checked items of the questionnaire every day for completeness. Incomplete items were excluded. Five percent of the interviewed participants were 
randomly selected and re-interviewed by the first author.

\section{Laboratory method: CMV-specific} immunoglobulin (Ig) IgG and IgM were analyzed by using the ELISA test kits (Diagnostic Automation, Inc., USA) according to manufacturer's guideline. Briefly, purified CMV antigen is coated on the surface of micro wells. Patient serum was then added to wells. If the antigen is present, then it will bind to the CMV $\mathrm{IgM} / \mathrm{IgG}$ specific antibody. All unbound materials are washed away and an enzyme conjugate is added to the well. The conjugate, then binds to the antibody-antigen complex. Excess enzyme conjugate is washed off and TMB Chromogenic Substrate is added. Intensity of the color generated by the bound conjugate is proportional to the amount of $\operatorname{IgG} / \mathrm{IgM}$ specific antibody present in the sample. Results are then read by a micro-well reader compared in a parallel manner with calibrator and controls. Quantitative analysis for CMV (IgG and IgM) and rubella (IgM) were performed, and the assay result interpreted as $\mathrm{IU} / \mathrm{mL}$. The manufacturer's instructions were followed for the cutoff points, which was $<1.1$ $\mathrm{IU} / \mathrm{mL}$ for CMV IgG and IgM. Results $<1.0 \mathrm{OD}$ value was considered negative for rubella IgM.

Data Analysis: The data were entered (with double entry) and cleaned with Epidata version 3.1, and analyzed by using SPSS version 20. Statistical significance was considered when Pvalue $<0.05$. CMV-IgG, IgM and Rubella IgM prevalence was determined by dividing the number of infected individuals to the total number of individuals screened for CMV and Rubella infection. Frequency distribution tables were used to quantify participants' age range, gestation, occupation, parity and risk factors of CMV positivity rate. Chi-square and Fisher's exact test was used to see the association of risk factors to CMV prevalence rate. Multivariate and univariate logistic regression analysis was used to quantify the effect of different clinical and obstetrical risk factors on CMV seroprevalence. Ninty-five percent confidence intervals were calculated for odds ratio. Values were considered statistically significant when $\mathrm{P}$-value $<0.05$.

Individuals who were positive for Rubella infection were low in number. Therefore, a regression was not applicable to see statistically significant association between the dependent and independent factor.
Ethical approval: Ethical approval for this study was obtained from the Institutional Review Board (IRB) of St.Paul's Hospital Millennium Medical College Research Ethics Committee (ref: 2014/P.M23/119) with 16/05/2014 date of approval. Women gave written informed consent before taking part in the study. All infected mothers received a serious follow-up by obstetricians, and treatment was also given.

\section{RESULTS}

\section{Socio-demographic and obstetrical} characteristics: A total of 200 pregnant women were enrolled in the study. The mean (SD) of maternal age, parity and gestational age were 26.7

Table 1: Socio-demographic variables of 200 pregnant women at St.Paul's Hospital Millennium Medical College, Addis Ababa, Ethiopia, 2014.

\begin{tabular}{lcc}
\hline Variable & Frequency & Percent \\
\hline Maternal Age & & \\
$<19$ & 7 & 3.5 \\
$20-25$ & 87 & 43.5 \\
$26-31$ & 73 & 36.5 \\
$32-37$ & 33 & 16.5 \\
Educational status & & \\
Illiterate & 38 & 19.0 \\
Primary & 57 & 28.5 \\
Secondary & 64 & 32.0 \\
Certificate & 26 & 13.0 \\
Diploma & 9 & 4.5 \\
Degree & 6 & 3.0 \\
Marital status & & \\
Married & 197 & 98.5 \\
Other & 3 & 1.5 \\
Occupation & & \\
Civil servant & 14 & 7.0 \\
Businesswoman & 18 & 9.0 \\
Housewife & 133 & 66.5 \\
Student & 5 & 2.5 \\
Others & 30 & 15.0 \\
Gestational Age & & \\
$1^{\text {st }}$ Trimester & 17 & 8.5 \\
$2^{\text {nd }}$ Trimester & 44 & 22.0 \\
$3^{\text {rd }}$ Trimester & 139 & 69.5 \\
Parity & & \\
0 & 65 & 32.5 \\
1 & 15 & 7.5 \\
2 & 58 & 29.0 \\
3 & 40 & 20.0 \\
>4 & 22 & 11.0 \\
\hline Note Gesta
\end{tabular}

Note: Gestational age was in week then converted to the categories. 
(4.7) years, 1.75 (1.5), 7.3(2.2) months, respectively. Almost all, 197(98.5\%), of the participants were married, and 64(32. \%) completed a secondary education. More than half $(66.5 \%)$ of the participants were housewives; 14 (7.0\%) were government employees and the least $5(2.5 \%)$ were students. Regarding gestational age distribution, nearly two third of the mothers, $139(69.5 \%)$, were in third trimester pregnancy and followed by $22.0 \%$ second trimester pregnancy (Table 1).

The mean CMV positivity age was 26.1 with standard deviations' of 4.9. The frequency of CMV infection was highest among pregnant women in the $3^{\text {rd }}$ trimester $(69.5 \%)$, those with second and first trimester pregnancy 21.5 and $9.0 \%$ respectively. More than $68 \%$ of the housewives were positive for the virus (Table 2).

Table 2: Distributions of CMV with Obstetrical, socio-demographical and clinical characteristic of the pregnant women in St.Paul's Hospital Millennium Medical College, Addis Ababa, Ethiopia 2014.

\begin{tabular}{|c|c|c|c|c|c|}
\hline & $\begin{array}{c}\text { Total } \\
(\mathbf{N}=\mathbf{2 0 0})\end{array}$ & $\begin{array}{l}\text { IgM positive } \\
(\mathrm{N}=\mathbf{3 1})\end{array}$ & $\begin{array}{c}\mathbf{P}- \\
\text { value }\end{array}$ & $\begin{array}{c}\text { IgG positive } \\
(\mathrm{N}=177)\end{array}$ & $\begin{array}{c}\text { P- } \\
\text { Value }\end{array}$ \\
\hline Age in Year & $26.7(4.7)$ & $25.67(4.6)$ & & $26.1(4.9)$ & \\
\hline \multicolumn{6}{|l|}{ Age group } \\
\hline$\leq 20$ & $17(8.5)$ & $4(12.9)$ & \multirow[t]{4}{*}{0.8} & $15(8.5)$ & \multirow[t]{4}{*}{0.3} \\
\hline $20-25$ & $77(38.5)$ & $12(38.7)$ & & $64(36.2)$ & \\
\hline $26-31$ & $73(36.5)$ & $11(35.5)$ & & $68(38.4)$ & \\
\hline $32-37$ & $33(16.5)$ & $4(12.9)$ & & $30(16.9)$ & \\
\hline \multicolumn{6}{|l|}{ Educational Status } \\
\hline Illiterate & $38(19.0)$ & 4(12.9) & \multirow[t]{5}{*}{0.5} & $31(17.5)$ & \multirow[t]{5}{*}{0.1} \\
\hline Primary & $57(28.5)$ & $12(38.7)$ & & $53(29.9)$ & \\
\hline Secondary & $64(32.0)$ & $11(35.5)$ & & $60(34.0)$ & \\
\hline Certificate & $26(13.0)$ & $2(6.4)$ & & 21(11.9) & \\
\hline Higher education & $15(7.5)$ & $2(6.4)$ & & $12(6.8)$ & \\
\hline \multicolumn{6}{|l|}{ Occupation } \\
\hline Civil servant & $14(7.0)$ & $1(3.2)$ & \multirow[t]{3}{*}{0.7} & $12(6.8)$ & \multirow{3}{*}{0.3} \\
\hline Housewife & $133(66.5)$ & $21(67.7)$ & & $121(68.4)$ & \\
\hline Business woman,Student \& others & $53(26.5)$ & $9(29.0)$ & & $44(24.8)$ & \\
\hline \multicolumn{6}{|l|}{ Gestational age in month } \\
\hline $1^{\text {st }}$ Trimester & $17(8.5)$ & $1(3.2)$ & \multirow[t]{3}{*}{0.5} & $16(9.0)$ & \multirow{3}{*}{0.7} \\
\hline $2^{\text {nd }}$ Trimester & $44(22.0)$ & $8(25.8)$ & & $38(21.5)$ & \\
\hline $3^{\text {rd }}$ Trimester & $139(69.5)$ & $22(71.0)$ & & $123(69.5)$ & \\
\hline \multicolumn{6}{|l|}{ Number of parity } \\
\hline 0 & $65(32.5)$ & $11(35.5)$ & \multirow[t]{5}{*}{0.4} & $56(31.6)$ & \multirow[t]{5}{*}{0.3} \\
\hline 1 & $15(7.5)$ & $1(3.2)$ & & $14(7.9)$ & \\
\hline 2 & $58(29.0)$ & $9(29.0)$ & & $55(31.1)$ & \\
\hline 3 & $40(20.0)$ & $4(12.9)$ & & $33(18.6)$ & \\
\hline$\geq 4$ & $22(11.0)$ & $6(19.4)$ & & 19(10.7) & \\
\hline \multicolumn{6}{|l|}{ No. children in house } \\
\hline 0 & $67(33.5)$ & $10(32.2)$ & \multirow[t]{4}{*}{0.8} & $57(32.2)$ & \multirow[t]{4}{*}{0.4} \\
\hline 1 & $50(35.0)$ & $7(22.6)$ & & $47(26.5)$ & \\
\hline 2 & $49(24.5)$ & $7(22.6)$ & & $44(24.9)$ & \\
\hline+3 & $34(17.0)$ & $7(22.6)$ & & $29(16.4)$ & \\
\hline
\end{tabular}


Table 2 continued...

\begin{tabular}{|c|c|c|c|c|c|}
\hline \multicolumn{6}{|c|}{ Seven month of child (F-test) } \\
\hline No & $193(96.5)$ & $29(93.5)$ & & $171(96.6)$ & \\
\hline Yes & $7(3.5)$ & $2(6.5)$ & 0.29 & $6(3.4)$ & 0.58 \\
\hline \multicolumn{6}{|c|}{ History of abortion (F-test) } \\
\hline No & $152(76.0)$ & $24(77.4)$ & & $132(74.6)$ & \\
\hline Yes & $48(24.0)$ & $7(22.5)$ & 1.00 & $45(25.4)$ & 0.298 \\
\hline \multicolumn{6}{|c|}{ Frequency of abortion (F-test) } \\
\hline 0 & $152(76.0)$ & $24(77.4)$ & & $132(74.6)$ & \\
\hline 1 & $34(17.0)$ & $4(12.9)$ & & $33(18.6)$ & \\
\hline$\geq 2$ & $14(7.0)$ & $3(9.7)$ & & $12(6.8)$ & \\
\hline \multicolumn{6}{|c|}{ Child death (F-test) } \\
\hline No & $186(93.0)$ & $30(96.8)$ & & $175(98.9)$ & \\
\hline Yes & $24(7.0)$ & $1(3.2)$ & 0.45 & $2(1.1)$ & 0.70 \\
\hline \multicolumn{6}{|c|}{ Mental retarded child (F-test) } \\
\hline Yes & $198(99.0)$ & $28(90.3)$ & 0.28 & $165(93.2)$ & 1.00 \\
\hline No & $2(1.0)$ & $3(9.7)$ & & $12(6.8)$ & \\
\hline \multicolumn{6}{|c|}{ Long term fever (F-test) } \\
\hline No & 194(97.0) & $29(93.5)$ & 0.23 & $173(97.7)$ & 0.14 \\
\hline Yes & $6(3.0)$ & $2(6.5)$ & & $4(2.3)$ & \\
\hline
\end{tabular}

Note: Data are as number and percentage, Chi-square, Fisher's Test. Gestational age was in week then converted to the categories, marital status was expressed in four categories (Married, Divorced, Separated, Widowed), Occupation were categorized based on their life style status. Abortion was recorded if there is any either of spontaneous abortion or medical termination. Long term fever $=$ a fever last longer than three or four days after noticed by a pregnant women . Number of children $=$ toddlers.

Seroprevalence: Out of the total 200 pregnant women, $177(88.5 \%$; 95\% CI: 84.0-94.0) were positive for anti-CMV-IgG antibodies and 31(15.5\%; 95\% CI: 10.5-21.0) were positive for CMV-IgM. Twenty-two (11.0\%) individuals were sero-negative for CMV. All except one CMV-IgM positive pregnant women were positive for CMVIgG. These were categorized into four types of responses. The first category was with previous exposure CMV [IgG (+) plus $\operatorname{IgM}(-)]$. This constituted $73.5 \%$ of the women. The second group was those with active (primary/latent) infection $[\operatorname{IgG}(+)$ plus IgM (+)] and this consisted of $15.0 \%$ respondents. The third group also had twenty-two women who were susceptible to primary CMV infection [IgG (-) plus $\operatorname{IgM}(-)]$. The last category of women was those with [IgG (-) plus $\operatorname{IgM}(+)]$, and therefore, one individual was included in this category, and had a recent primary infection (Table 3 ). 
Table 3: Seroprevalence of CMV-specific IgG and IgM, and Rubella IgM antibodies among pregnant women $(\mathrm{n}=200)$ in St.Paul's Hospital millennium Medical College, Addis Ababa, Ethiopia 2014.

\begin{tabular}{lccl}
\hline Immune responses & Number & Percent & Interpretation \\
\hline $\operatorname{IgG}(+) \operatorname{IgM}(-)$ & 147 & 73.5 & \\
& & & Previous Exposure \\
$\operatorname{IgG}(+) \operatorname{IgM}(+)$ & 30 & 15.0 & \\
& 22 & 11.0 & $\begin{array}{l}\text { Active (Primary/Latent) infection } \\
\text { IgG(-) IgM (-) }\end{array}$ \\
$\operatorname{IgG}(-) \operatorname{IgM}(+)$ & 1 & 0.5 & $\begin{array}{l}\text { Recent primary infection } \\
\text { IgM(+) }\end{array}$ \\
\hline
\end{tabular}

Risk Factors: Among the participants, $8.5 \%$ were between age groups of $\leq 20,38.5 \%$ were between $21-25,36.5 \%$ were between $26-31$ and $16.5 \%$ were above 32 . The prevalence of infection among age groups $\leq 20,21-25,26-31$ and $\geq 32$ was $88.2 \%$ (CI: $0.1-3.2$ ), $83.1 \%$ (CI: $0.3-10.3$ ), 93.1\% (CI: $0.2-8.8$ ), and $90.1 \%$ respectively. However, multivariate logistic regression analysis showed that no stastically significant variables were found. There was no significant association detected between sero-positivity rate of cytomegalovirus and educational status, occupation, gestational age and parity.

None of the pregnant women had history of jaundice; whereas $24.0 \%$ had history of abortion, of whom $17.0 \%$ had at least one frequency of abortion. Among those who had history of abortion, 93.7\% (CI: 0.6-38.6) were sero-positive. From the participants, $7.0 \%$ had a history of dead child. Among mothers who had history of child lose, $85.7 \%$ (CI: $0.3-6.3$ ) were positive for the infection. Pregnant women who had no toddler in the house hold were $33.5 \%$. Among the mothers who had no children in the household, $85.1 \%$ were seropositive. However, there was no single independent factor for the infection of cytomegalovirus (Table 4). 
Table 4: Association of CMV with Obstetrical, socio-demographical and clinical characteristic of the pregnant women in SPHMMC, Addis Ababa, Ethiopia 2014

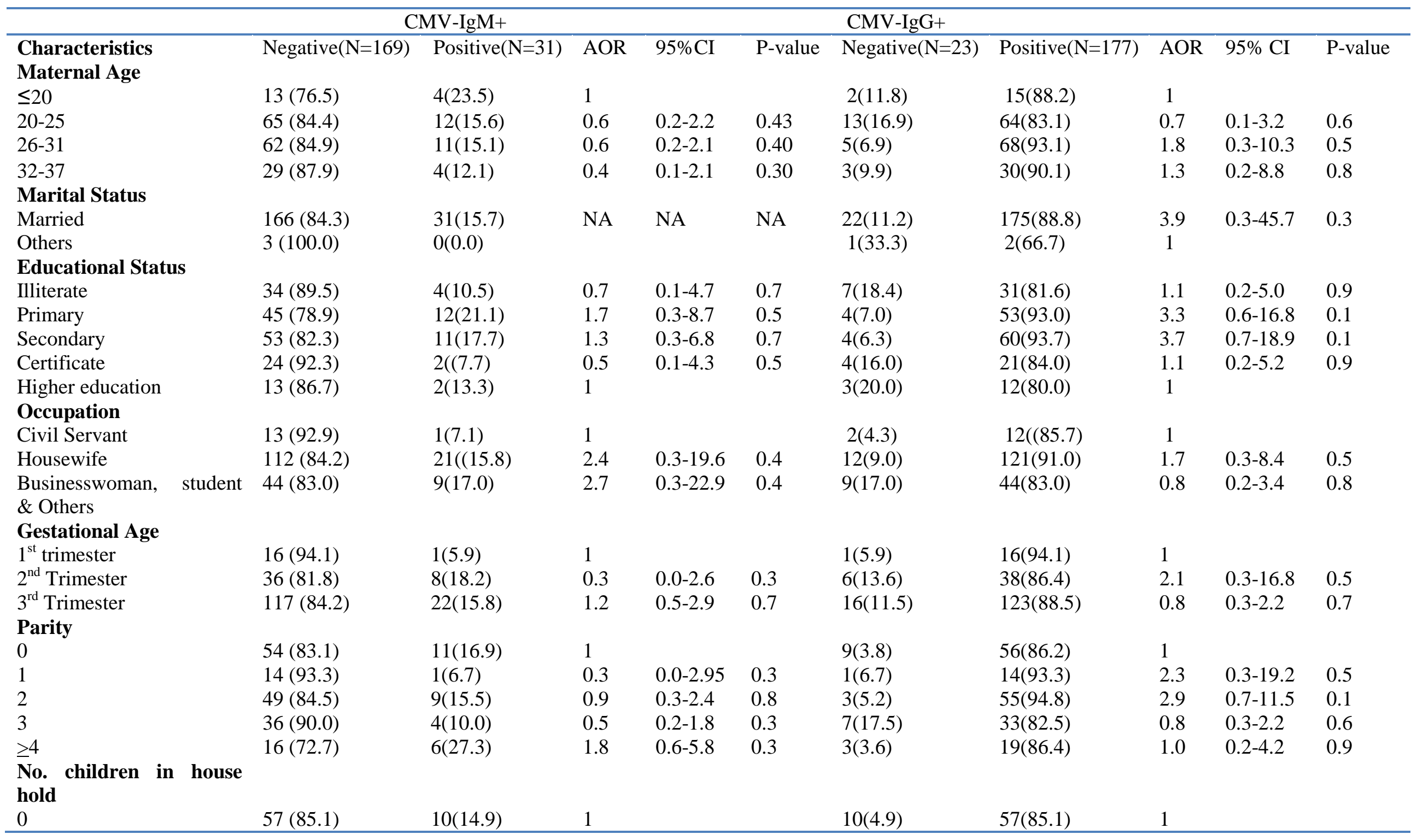




\begin{tabular}{|c|c|c|c|c|c|c|c|c|c|c|}
\hline 1 & $43(86.0)$ & $7(14.0)$ & 0.9 & $0.3-2.6$ & 0.9 & $3(6.0)$ & $47(94.0)$ & 2.7 & $0.7-10.6$ & 0.1 \\
\hline 2 & $42(85.7)$ & $7(14.3)$ & 0.9 & $0.3-2.7$ & 0.9 & $5(10.2)$ & $44(89.8)$ & 1.5 & $0.5-4.8$ & 0.5 \\
\hline$\geq 3$ & $27(79.4)$ & $7(20.6)$ & 1.5 & $0.5-4.3$ & 0.5 & $5(4.7)$ & $29(85.3)$ & 1.0 & $0.3-3.2$ & 1.0 \\
\hline \multicolumn{11}{|c|}{ Child death occurrence } \\
\hline No & $158(84.9)$ & $28(15.1)$ & 1 & & & 21(11.3) & $165(88.7)$ & 1 & & \\
\hline Yes & $11(78.6)$ & $3(21.4)$ & 1.5 & $0.4-5.9$ & 0.6 & $2(14.3)$ & $12(85.7)$ & 1.3 & $0.3-6.3$ & 0.7 \\
\hline Seven month child & & & & & & & & 1 & & \\
\hline No & $164(85.0)$ & $29(15.0)$ & 1 & & & $22(11.4)$ & 171(88.6) & 1 & & \\
\hline Yes & $5(71.4)$ & $2(28.6)$ & 2.3 & $0.4-12.2$ & 0.3 & $1(14.3)$ & $6(85.7)$ & 1.3 & $0.1-11.3$ & 0.8 \\
\hline \multicolumn{11}{|l|}{ Abortion } \\
\hline No & $128(84.2)$ & $24(15.8)$ & 1 & & & $20(13.2)$ & $132(86.8)$ & 1 & & \\
\hline Yes & $41(85.4)$ & $7(14.6)$ & 0.9 & $0.4-2.3$ & 0.8 & $3(6.3)$ & $45(93.7)$ & 2.3 & $0.6-8.0$ & 0.2 \\
\hline \multicolumn{11}{|c|}{ Frequency of Abortion } \\
\hline 0 & $128(84.2)$ & $24(15.8)$ & 1 & & & $20(13.2)$ & 132(86.8) & 1 & & \\
\hline 1 & $30(88.2)$ & $4(11.8)$ & 0.7 & $0.2-2.2$ & 0.5 & $1(2.9)$ & $33(97.1)$ & 5.0 & $0.6-38.6$ & 0.1 \\
\hline$\geq 2$ & $11(78.6)$ & $3(21.4)$ & 1.5 & $0.4-5.6$ & 0.6 & $2(14.3)$ & $12(85.7)$ & 1.0 & $0.2-4.4$ & 0.9 \\
\hline \multicolumn{11}{|c|}{ Mental retarded child } \\
\hline No & $168(84.8)$ & $30(15.2)$ & 1 & & & $23(11.6)$ & $175(88.4)$ & NA & & NA \\
\hline Yes & $1(50.0)$ & $1(50.0)$ & 5.6 & $\begin{array}{l}0.34- \\
92.0\end{array}$ & 0.2 & 0 & $2(100.0)$ & & & \\
\hline \multicolumn{11}{|l|}{ Long time fever } \\
\hline No & $165(85.1)$ & $29(14.9)$ & 1 & & & $21(10.8)$ & $173(89.2)$ & 1 & & \\
\hline Yes & $4(66.7)$ & $2(33.3)$ & 2.8 & $0.5-16.3$ & 0.2 & $2(33.3)$ & $4(66.7)$ & 4.1 & $0.7-23.8$ & 0.1 \\
\hline
\end{tabular}

Data are expressed in Number, Percent, $\mathrm{OR}=$ Odds Ratio, $\mathrm{CI}=$ Confidence Interval

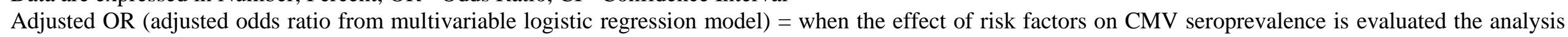
was adjusted for factors listed in the table. In the table less risk factor in the other study were used as a reference in this study. 


\section{DISCUSSION}

This is the first study to examine the rates of CMV infection among pregnant women in Ethiopia. The overall incidence rate of $\mathrm{CMV}$ IgG among pregnant women in our study was $88.5 \%$, which is similar with other studies in different African countries: $97.5 \%$ in Sudan (14), 96\% in Egypt (15), 92\% in Nigeria (16) and 87\% in Gambia (17). However, the results of this study were higher than those reported in developed countries. A relatively low sero-prevalence, $40 \%-60 \%$, is reported, $46.8 \%$ from France (18), $56.3 \%$ in Finland (19) nd 60\% in the United States (20). It seems that the prevalence of CMV infection observed in this study was similar to that reported in other developing communities but higher than in the developed one. This may be attributed to the low socioeconomic status and poor hygienic practices which might play significant roles in increasing rate of CMV infection.

In the present study, the sero-prevalence of CMV IgM was $15.5 \%$ among the pregnant women, which reflected an active recent infection and reactivation of the virus. This finding was 4-7 times higher than those in other different developing countries; $4 \%$ in Nigeria (16), 6\% in Sudan (14), 2.5\% in Iran (21), $1.7 \%$ in Korea (22) and/or even developed world studies from Belgium, Brazil, Taiwan, Cuba and Finland (2327). This might be due to low socio-economic status, the number of toddlers and poor hygienic practice. Poor hygienic practice, in particular, is a key source for the prevalent of infection. However, a similar rate of active infection has been reported from Poland (28), 15.9\% in Kashmir valley (29) and India (30). Luckily, one woman $(0.5 \%)$ out of the 31 IgM-positive Ethiopian women tested was IgG negative, indicating probably of a recent primary infection.

In the current study, there was no independent factor which will increase the infection rates of cytomegalovirus among pregnant women $(\mathrm{P} \geq 0.05)$. These results suggest that all maternal age groups have equal chance of being infected by CMV infection. The current finding is in agreement with other studies $(14,16)$. However, our finding is in contrast with other studies, illiterate women and women with high parity were at higher risk for $\mathrm{CMV}$ infection (21,31-33). This might be due to the differences in socio-demographic characteristics, various cultures and behaviors among these settings might have influence and determine epidemiology of CMV. In another study, it was found that low socioeconomic status is a strong risk factor for acquisition CMV infection (32).

In the current study, 22(11.0\%) of the participants were observed to be susceptible to primary CMV infection during their pregnancy. These women are at risk for congenital infection resulting from a primary infection due to maternal primary CMV infection, which leads to fetal infection in approximately $40 \%$ of cases (34). Since the incidence rate of primary infection among pregnant women is high, they are a critical group because the risk of congenital infection/following/after/resulting from a primary infection is much higher during primary infection in the pregnant women $(2,34)$. Therefore, it would be beneficial to properly inform this category of women about the need for further investigations to detect prenatal infection and planning of appropriate intervention such as use of hyperimmune globulin or consented termination of pregnancy as an option.

In many developing countries, the burden of CRS is under-estimated (35). Also, Ethiopia lacks information regarding the burden of CRS. In this study, Rubella specific IgM was $2.0 \%$ from pregnant women. This is in comparabel with other study; $2 \%$ in Sudan (36). Many cases of rubella are identified every year in Ethiopia by the measles surveillance system. However, there is currently no effective intervention for rubella in the country. Thus, an intensive type of research is important for the decision to introduce rubellacontaining vaccine in the national immunization program.

Possible preventive measures including improved hygiene behavior of sero-negative pregnant women should be emplaced and routine maternal screening for primary infection using $\mathrm{IgG}$ avidity has to be made. Once diagnosed with the cytomegalovirus infection, treatment with hyperimmune globulin and safe administration of oral ganciclovir to mothers of CMV-infected fetuses, with no teratogenic side effects when given in the early stages of pregnancy should be supported $(37,38)$.

This study brought a new epidemiology of etiological agent in Ethiopia. It showed the high prevalence of cytomegalovirus infection in the setting. The study also showed the high prevalence 
of primary (recent and/or re-activation) infection and indicated the high risk of feta anomalies. Since this is the first study in the setting, the significance of information that contained in the study is not undermined by clinicians, researchers and policy makers.

The following limitations should be taken into consideration. These include failure to use CMV IgG avidity test, which helps to identify between primary infection and reactivation. We were unable to address all the potential risk factors to CMV positivity like HIV/ADIS sero-status and income of the participants.

In general, this study showed that there is a high sero-prevalence rate of CMV infection among pregnant women at our center. It is also likely to be a reflection of the overall high prevalence among adult Ethiopians. In addition to detecting high prevalence of CMV, detecting recent infection of rubella worsens the outcome of the disease. This finding therefore helps to create awareness among clinicians in Ethiopia, that rapid and accurate diagnosis of CMV infection in pregnant women is critical to prevent major associated complications. Future studies, including large scale surveillance throughout Ethiopia, are needed before national screening and universal prevention measures are considered.

\section{ACKNOWLEDGEMENTS}

The authors are very grateful to St. Paul's Hospital Millennium Medical College, Dr.Zerihun Abebe, Dr. Lia Tadesse, and finance offices for their kind co-operation in addition to providing the fund. We are also grateful to Dr. Jason Bell for his kindness and unreserved co-operation starting from the project development and facilitating the reagent purchasing. Finally, we would like to thank all the patients for their willingness to participate in this study. Finally, we would not ignore the co-operation of the Ethiopian Public Health Institute for their collaboration.

\section{REFERENCES}

1. Casteels A, Naessens A, Gordts F, De Catte L, Bougatef A, Foulon W. Neonatal screening for congenital cytomegalovirus infections. $J$ Perinat Med. 1999;27:116-21

2. Kenneson A, Cannon MJ. Review and metaanalysis of the epidemiology of congenital cytomegalovirus (CMV) infection. Rev Med Virol. 2007; 17(4):253-76.

3. Richard LH. Human Cytomegalovirus. In: Murray PR, ed. Manual of Clinical Microbiology, 10th edn. Washington DC: ASM Press, 2007:1549-1559.

4. Rahav G, Gabbay R, Ornoy A, Shechtman S, Arnon J, Diav-Citrini O. Primary versus nonprimary cytomegalovirus infection during pregnancy, Israel. Emerg Infect Dis 2007; 13:1791-1793.

5. Wang C, Zhang X, Bialek S, Cannon MJ. Attribution of congenital cytomegalovirus infection to primary versus non-primary maternal infection. Clin Infect Dis, 2011; 52: e11-e13. doi:10.1093/cid/ciq085.

6. Cannon MJ, Hyde TB, Schmid DS. Review of cytomegalovirus shedding in bodily fluids and relevance to congenital cytomegalovirus infection. Rev Med Virol, 2011; 21: 240-255.

7. Manicklal S, Emery VC, Lazzarotto T, Boppana SB, and Gupta RK. The "Silent" Global Burden of Congenital Cytomegalovirus. Clinical Microbiology Reviews, 2013; 26(1): 86-102.

8. Stagno S, Cytomegalovirus. in Infectious diseases of the fetus and newborn infant, ed. by Remington JS, Klein JO (Philadelphia, W.B. Saunders Company,2001), pp. 389-424.

9. Ojala P, Vesikari T, and Elo O. Rubella during pregnancy as a cause of congenital hearing loss. Am J Epidemiol. 1973; 98(5):395-401.

10. Centers for Disease Control and Prevention (CDC), Progress toward control of rubella and prevention of congenital rubella syndrome worldwide, 2009. MMWR Morb Mortal Wkly Rep. 2010; 59(40):1307-10.

11. Barreto J, Sacramento I, Robertson SE, Langa J, de Gourville E, Wolfson L et al. Antenatal rubella serosurvey in Maputo, Mozambique. Trop Med Int Health. 2006; 11(4):559-64.

12. Robertson. SE, Featherstone DA, Gacic-Dobo M, and Hersh BS. Rubella and congenital rubella syndrome: global update. Rev Panam Salud Publica. 2003; 14(5):306-15.

13. Pass RF, Zhang C, Evans A, Simpson T, Andrews $\mathrm{W}$, Huang $\mathrm{M}$, et al. Vaccine prevention of maternal cytomegalovirus infection. N Engl J Med. 2009 ;360(12):11919 
14. Khairi SI, Intisar KS, Enan KH, Ishag MY, Baraa AM and Ali YH. Seroprevalence of cytomegalovirus infection among pregnant women at Omdurman Maternity Hospital, Sudan. J. Med. Lab. Diagn; 2013; 4(4): 45-49.

15. Nawawy A el, Soliman AT, Azzouni O el, Amer el-S, Karim MA, Demian $S$ et al. Maternal and neonatal prevalence of toxoplasma and cytomegalovirus (CMV) antibodies and hepatitis- $\mathrm{B}$ antigens in an Egyptian rural area. J Trop Pediatr, 1996; 42(3):154-7.

16. Ephraim OE, Oyinlola O, Patrick VL, Joseph UO, Charles JE. Seroprevalence and risk factors for cytomegalovirus infection among pregnant women in southern Nigeria. JMID, 2013; 3 (3): 123-127.

17. Bello C, Whittle H. Cytomegalovirus infection in Gambian mothers and their babies. J Clin Pathol, 1991; 44(5): 366-9.

18. Picone OC, Vauloup F, Cordier AGI, Parent DuC, Senat MV, Frydman R et al. A 2-year study on cytomegalovirus infection during pregnancy in a French hospital. Br. J. Obstet. Gynecol, 2009; 116(6):818-823.

19. Alanen A, Kahala K, Vahlberg T, Koskela P, Vainionpää R. Seroprevalence, incidence of prenatal infections and reliability of maternal history of varicella zoster virus, cytomegalovirus, herpes simplex virus and parvovirus B19 infection in South- Western Finland. BJOG: Int. J. Obstet. Gynecol, 2005; 112(1):50-56.

20. Staras SA, Dollard SC, Radford KW, Flanders WD, Pass RF, and Cannon MJ., "Seroprevalence of cytomegalovirus infection in the United States, 1988-1994," Clinical Infectious Diseases, 2006; 43(9): 1143-1151.

21. Bagheri L, Mokhtarian H, Sarshar N, Ghahramani M. Seroepidemiology of cytomegalovirus infection during pregnancy in Gonabad, east of Iran: a cross-sectional study. J. Res. Health Sci, 2012; 12 (1):38-44.

22. Seo S, Cho Y, Park J. Serologic screening of pregnant Korean women for primary human cytomegalovirus infection using IgG avidity test. Korean J. Lab. Med, 2009; 29(6):557562.

23. Naessens A, Casteels A, Decatte L, Foulon W. A serologic strategy for detecting neonates at risk for congenital cytomegalovirus infection. J Pediatr, 2005; 146(2):194-197.
24. Spano LC, Gatti J, Nascimento JP, Leite JP: Prevalence of human cytomegalovirus infection in pregnant and non-pregnant women. J Infect, 2004; 48(3):213-220.

25. Chen MH, Chen PC, Jeng SF, Hsieh CJ, Su FC, Liao HF et al. High perinatal seroprevalence of cytomegalovirus in northern Taiwan. J Paediatr Child Health 2008; 44(4):166-169.

26. Correa CB, Kouri V, Verdasquera D, Martinez PA, Alvarez A, Aleman Y et al. HCMV seroprevalence and associated risk factors in pregnant women, Havana City, 2007 to 2008. Prenat Diagn 2010; 30(9):888-892.

27. Mustakangas P, Sarna S, Ammala P, Muttilainen M, Koskela P, Koskiniemi M. Human cytomegalovirus seroprevalence in three socioeconomically different urban areas during the first trimester: a population-based cohort study. Int $J$ Epidemiol, 2000; 29(3):587-591.

28. Gaj Z, Rycel M, Wilczynski J, Nowakowska D: Seroprevalence of cytomegalovirus infection in the population of Polish pregnant women. Ginekol Pol; 2012; 83(5):337-341.

29. Lone R, Fomda BA, Thokar M, Wani T, Kakru D, Shaheen R et al. Seroprevalence of cytomegalovirus in Kashmir valley. $J K$ Practitioner, 2004; 11(4):261-262.

30. Chakravarty A, Kashyap B, Rathi K. The seroepidemiological study on cytomegalovirus in women of child-bearing age with special reference to pregnancy and maternal-fetal transmission. Indian J Pathol Microbiol, 2005; 48(4):518-521.

31. Hamdan ZH, Abdelbagi IE, Nasser NM, Adam I. Seroprevalence of cytomegalovirus and rubella among pregnant women in western Sudan. Virol. J. 2011; 8:217-220.

32. Bate SL, SC Dollard, MJ Cannon, Cytomegalovirus seroprevalence in the United States: the national health and nutrition examination surveys, 1988-2004. Clin Infect Dis, 2010; 50(11):1439-47.

33. Walmus BF, Yow MD, Lester JW, Leeds L, Thompson PK, Woodward RM. Factors predictive of cytomegalovirus immune status in pregnant women. J Infect Dis, 1988; 157(1):172-7.

34. Fowler KB, Stagno S, Pass RF. The outcome of congenital cytomegalovirus infection in 
relation to maternal antibody status. $N$ Engl $J$ Med, 1992; 326:663-667.

35. Banatvala JE, Brown DW: Rubella. Lancet, 2004; 363(9415):1127-1137.

36. Adam O, Ali AK, Hübschen JM, and Muller CP. Identification of congenital rubella syndrome in Sudan. BMC Infectious Diseases, 2014; 14:305

37. Adler SP, Nigro G, Pereira L. Recent advances in the prevention and treatment of congenital cytomegalovirus infections. Semin Perinatol, 2007; 31 (1):10-8.

38. Cahill AG, Odibo AO, Stamilio DM, Macones GA. Screening and testing for primary cytomegalovirus in pregnancy: where do we stand? A decision-analytic and economic analysis. Am J Obst Gynecol, 2009; 201:466e1-7. 